\title{
Imitation in autism. A preliminary research note
}

\author{
M. Heimann'1, E. Ullstadius ${ }^{1}$, S.-O. Dahlgren ${ }^{1}$ and C. Gillberg ${ }^{2}$ \\ Departments of ${ }^{1}$ Psychology and ${ }^{2}$ Child and Adolescent Psychiatry, University of Göteborg, \\ Sweden \\ Correspondence to: M. Heimann, Department of Psychology, Box 14158, S-400 20 \\ Göteborg, Sweden
}

\begin{abstract}
Previous studies have claimed that children with autism are poor imitators and a lack of imitative capacity has been included by some investigators as one early sign of autism. Presented here are results from a pilot study focusing on observed imitation after presenting 15 tasks to five children with autism (mental age 25-51 months). Imitation tasks involving simple object manipulation, vocal responses, facial and manual gestures, and object substitution were presented to each child. The performance of the children with autism is compared with (1) three normal 4-year-old children (for all 15 tasks), and (2) observations from 28 healthy 1-year-olds (for 10 of the tasks used). The findings indicate that the autistic group displayed the highest level of imitation on object manipulation and vocal tasks while object substitution, facial, and motor imitation acts seemed to be difficult for children with autism. However, the small number of children included as well as the individual variation observed among the autistic subjects precludes any definite conclusions from these pilot observations. It is hypothesized that imitation in children with autism has to be studied separately for different domains and probably also for different subgroups within the autistic population.
\end{abstract}

Keywords: Autism - Imitation - Infants - Preliminary study - Pre-school children

\section{INTRODUCTION}

Earlier studies have suggested that children with infantile autism/autistic disorder (APA, 1980, 1987) are poor imitators (Ritvo and Provence, 1953; Lovaas et al., 1967; DeMyer et al., 1972; Hammes and Langdell, 1981; Ohta, 1987), and a lack of imitative capacity has been included by some investigators as one of the early signs of autism (Krug et al., 1980; Sauvage et al., 1987; LeCouteur et al., 1989; Rogers and Pennington, 1991). However, children with autism are also known to display extreme imitative responses like echolalia and echopraxia (Ricks and Wing, 1975; Shapiro and Lucy, 1978; Ford, 1989), and not all studies have found a strong lack of imitative capacity among children with autism (Morgan et al., 1989).

In one of the earliest reports on imitation in young children with autism, Ritvo and Provence (1953) noted poor responses on tasks requiring motor responses as well as tasks focusing on object manipulation, sound and drawing. Six children were observed but no control group was used. Ritvo and Provence concluded that imitation is part of the identification process and that the low levels of imitation noted among the autistic or early schizophrenic children indicated an insufficient differentiation between the self and the non-self. Later, Lovaas et al. (1967) also noted an imitation deficit among children with autism and started training of imitation skills. Today support exists for the positive effect of imitative play on the child's be- haviour (Dawson and Galpert, 1987; Nadel and Fontaine, 1989)

The first experimental study on imitation skills among children with autism was reported by DeMyer et al. (1972) who found that children with early psychosis (autism or childhood schizophrenia) displayed lower levels of body and motor-object imitation than the control subjects. Moreover, they found that the children in the experimental group used objects better when allowed to play with them spontaneously than after modelling. Furthermore, several reports have observed specific deficits in the ability to imitate gestures (e.g. Bergès and Lézine, 1965; Ohta, 1987) and a low level of motor imitation abilities has been interpreted as a specific handicap within the neurodevelopmental area (Jones and Prior, 1985).

A deficit in imitation of symbolic acts has been noted by some investigators (Wing et al., 1977; Hammes and Langdell, 1981; Riguet et al., 1981; Sigman and Ungerer, 1984). Hammes and Langdell, who studied eight children with autism and eight children with mental retardation as controls, found that their autistic group did imitate at a basic level but that the mentally retarded children performed better on more symbolic and pretend-like tasks. They concluded that children with infantile autism probably have a major deficit for handling of symbolic gestures. This makes them poor in pretend play, a deficit that 
has recently been proposed as being one of the precursors to the observed inability among children with autism to develop a "theory of mind" (Baron-Cohen et al., 1985; Leslie, 1987). In addition, Hertzig et al. (1988) reported that children with autism also performed less well on tasks requiring imitation of affective stimuli.

An imitation deficit has furthermore been noted in retrospective reports (Sauvage et al., 1987; Dahlgren and Gillberg, 1989). Recently, Gillberg et al. (1990) confirmed this finding: "Difficulties in imitating movements" was one of the items on a questionnaire given to parents to aid discrimination of children with autism from normal children and those with mental retardation.

Moreover, most empirical studies tend to treat imitation as a skill unrelated to the domain in focus, and studies rarely discuss any individual differences. The literature on imitation in normal development has, however, come to recognize both differences in imitation between domains and individual differences (Bloom et al., 1974; Bates, 1979; Nelson et al., 1989).

Although an imitation deficit has been noted for gestures, objects, symbolic, and affective tasks, until recently no coherent theory of the development of imitation in children with autism existed. However, Rogers and Pennington (1991) presented a theoretical framework for understanding the early signs of autism in which they hypothesize that "early social capacities involving imitation, emotion sharing, and theory of mind are primarily and specifically deficient in autism" (p. 137). According to Rogers and Pennington early imitation should be viewed as a social skill and they stress that an early deficit in imitation may be quite handicapping to the very young child. An inability to imitate might slow down or hinder the early stages of self-development.

The observations to be reported here are based on a pilot study in which imitation among five children with autism was compared with (1) three normal 4-year-olds, and (2) 28 normal 1-year-olds. Our primary goal was (1) to study ways of observing imitation in young autistic children and (2) to investigate imitation within different domains. More specifically we wanted to investigate if tasks used in a previous study on healthy infants (Heimann, 1991) could be used in a future study investigating imitation in young children with suspected autism.

\section{METHOD}

\section{Subjects}

Infantile autism (IA) group. The subjects were four boys and one girl diagnosed according to the DSM-III (APA, 1980 ) as suffering from infantile autism. All five children also met the criteria for autistic disorder according to the DSM-III-R (APA, 1987). Two independent child psychiatrists examined the children and arrived at the same diagnosis in all five cases. Chronological age ranged from 39 to 62 months (see also Table I). Mental age was assessed by the Griffiths Developmental Scales (Griffiths, 1954; Swedish standardization: Alin-Åkerman and Nordberg, 1980) and the obtained developmental quotients (DQ) varied from 43 to 106 . The estimated mental age (MA) varied from 25 to 51 months. Mean chronological age at diagnosis was 46 months (range 34-67; one child received his final diagnosis after participating in this study).

Comparison group 1 (CG1). Comparison data were collected from three normal 4-year-olds (chronological age: 45-48 months). Their development was judged to be normal and age-appropriate by their parents and preschool teachers.

Comparison group 2 (CG2). Additional data from 28 healthy 12-month-old infants participating in a separate study on imitation during the first year of life (see Heimann, 1991) were also used for comparison purposes.

\section{Procedure}

IA group. A home visit was scheduled shortly after receiving the parents' consent for the children's participation. The home visit took approximately $1 \mathrm{~h}$ and consisted of three parts: (1) familiarization (not less than $5 \mathrm{~min}$ ); (2)

TABLE I. Subjects included in the IA group

\begin{tabular}{lcccccc}
\hline Case & Sex & CA & MA & DQ & AD & Associated handicaps \\
\hline 1 & M & 58 & 51 & 86 & 671 & ABR abnormalities \\
2 & M & 62 & 27 & 43 & 30 & SMR \\
3 & $\mathrm{~F}$ & 54 & 33 & 62 & 38 & MMR + elfin face \\
4 & $\mathrm{M}$ & 39 & 25 & 65 & 31 & - \\
5 & $\mathrm{M}$ & 42 & 44 & 106 & 32 & Astigmatism \\
\hline
\end{tabular}

$\mathrm{CA}$, chronological age in months; $\mathrm{MA}$, estimated mental age in months; $\mathrm{DQ}$, developmental quotient; $A D$, age when diagnosed according to medical records; SMR/MMR, severe or moderate mental retardation; $A B R$, auditory brain response.

${ }^{1}$ Case 1 had only a provisional diagnosis of IA when observed at 58 months; final diagnosis was received at 67 months. 
free play (mean length $3.4 \mathrm{~min}$, range $2.4-5.3 \mathrm{~min}$ ), and (3) elicited imitation (mean length $22.7 \mathrm{~min}$, range 17.2-36.0 min). All children were videotaped during free play and elicited imitation using a lightweight portable camera with a separate recording unit.

Free play. The child was allowed a brief period to explore the toys. During this period, the experimenter (E) sat on the floor with the toys spread out in front of her. The purpose was to see if any of the imitation tasks were produced spontaneously by the child while exploring the toys.

Elicited imitation. The imitation tasks were presented in a pre-set order. That is, this phase always started with a simple object manipulation task and ended with an object substitution task (see below for a description of all tasks). Two identical sets of toys (the same toys as in the free play part) were used throughout (one set for the child and one set for E). Every presentation was carried out twice, unless the child produced a complete imitative response after the first presentation. Moreover, a presentation was only carried out when $E$ judged the child to be attentive. No verbal clues were given indicating what was expected of the child except for verbal messages needed in order to catch and keep the child's attention (e.g. "look here!").

Comparison group 1. The procedure for the three children in CG1 was identical to the procedure described above for the IA group. All observations took place in the child's home. The home visit took approximately $30 \mathrm{~min}$ and consisted of three parts: (1) familiarization (not less than $5 \mathrm{~min}$ ); (2) free play (mean length $5.33 \mathrm{~min}$, range 5.0-6.0 $\mathrm{min}$ ), and (3) elicited imitation (mean length 12.0 min, range 9.0-14.0 $\mathrm{min}$ ).

Comparison group 2. The 28 children in CG2 participated in a longitudinal study on imitation during the first year of life. The 12 month observation took place in a laboratory setting at the Department of Psychology, University of Göteborg. Ten of the tasks used were identical with 10 of the tasks administered to the autistic children. Only data from these 10 tasks are included in the analysis.

Free play. Not included for CG2.

Elicited imitation. The imitation tasks were presented in a pre-set order, starting with a simple object manipulation task and ending with vocal imitation (see below for a description of all tasks). Overall the procedure for the children in CG2 was identical with the procedure described above for the IA group.

\section{Imitation tasks}

The following imitation tasks were used in the study. The IA group and CG1 received all of the tasks while CG2 only received numbers 1 to 10 .

\section{A Object manipulation}

1 E holds small wooden block in hand, then drops the block.

2 E builds a tower of two blocks.

3 E stirs with spoon in cup.

4 E pretends to drink from cup.

5 E brushes her hair with a soft brush.

\section{$B$ Vocal imitation}

6 A hand doll pretends to drink from cup, then says "Aaah!".

7 The hand doll holds a small wooden block, drops it and says "Oy!".

\section{$C$ Facial imitation}

8 E models tongue protrusion (E protrudes her tongue clearly a couple of times in order to elicit imitation of tongue protrusion).

9 E models mouth opening.

10 E sniffs flower.

\section{Motor imitation}

11 E waves bye-bye.

12 E puts hand over mouth after yawning.

13 E touches one ear, one knee and then the nose.

\section{E Object substitution}

14 Using the cup as a hat.

15 Pretending to drink using the brush as a cup.

An additional task intended to observe sequential imitation was administered to the IA group (Ullstadius et al., unpublished work). However no data from this task are reported here since none of the other two groups received that task making it impossible to compare performance between the groups.

\section{Coding and data analysis}

All responses were coded as belonging to one of three categories: (1) full imitation, (2) partial imitation or (3) no imitation. Full imitation was coded whenever the child correctly reproduced the act modelled. Partial imitation was coded whenever the child made an attempt to imitate but did not make a complete reproduction of the modelled behaviour. Imitation was only coded if the child responded no later than $10 \mathrm{~s}$ after the presentation. Thus, only immediate imitative responses are used for comparison. The category no imitation was used when the child either did not respond or did something completely different (e.g. started to play with other toys). Furthermore, responses that had been observed during free play were noted separately and not coded as imitation.

IA group. The videotapes were coded by two of the authors (S-OD, all tapes and $\mathrm{MH}$, part of two tapes). The obtained agreement was $90 \%$. 
Comparison groups 1 and 2. The coding was carried out by a senior undergraduate student (all the tapes for CG1), a psychologist outside the project (all the tapes for CG2), and one of the authors ( $\mathrm{MH}$, part of two tapes). In order to achieve an acceptable reliability, the coders trained until they reached an agreement in scoring imitative responses of at least $90 \%$.

Any difficulties that arose during the process of coding the tapes for any of the two groups were solved by reviewing the difficult tape until an agreement was reached. The very few instances of difficulties that occurred all focused upon judging an imitative response as full or partial.

\section{RESULTS}

\section{Performance by the IA group}

An overall analysis revealed that of a total of 92 presentations, 23 resulted in an imitative response judged as full or partial. As evident from Table II, all but one child (case
2) showed some imitation on the object manipulation tasks while only one or two of the children with autism displayed imitation when tasks in the other four groups were modelled. Thus, object manipulation tasks are more often imitated by the autistic children in our sample compared with tasks requiring vocal, facial or motor responses.

More specifically, two children imitated both vocal imitation tasks (cases 1 and 5), and two displayed some facial imitation (cases 1 and 3). In contrast, only one instance of imitation was noted for motor imitation (case 1). The tasks involving motor responses were the most difficult ones to present and we did not succeed in modelling any of these tasks to two of the autistic subjects (cases 4 and 5). Furthermore, a relatively low level of imitation was noted for object substitution tasks (imitation success cases 1 and 5).

Each child in the IA group received 15 presentations from the experimenter trying to elicit imitation. However, since a total of 15 tasks were used and each task could be presented twice, a total of 30 presentations would have

TABLE II. Individual imitative responses observed among children with autism (IA group, $n=5$ ), and normal 4 year olds (comparison group $1, n=3$ )

\begin{tabular}{|c|c|c|c|c|c|c|c|c|c|}
\hline & & \multicolumn{8}{|c|}{ Imitative responses displayed by the } \\
\hline & & \multicolumn{4}{|c|}{$\begin{array}{l}\text { A group } \\
\text { Case }\end{array}$} & \multicolumn{4}{|c|}{$\begin{array}{c}\text { Comparison group } 1 \\
\text { Subject }\end{array}$} \\
\hline & & 1 & 2 & 3 & 4 & 5 & 1 & 2 & 3 \\
\hline \multicolumn{10}{|c|}{ A Object manipulation } \\
\hline 1 & Drop block & 2 & 0 & 2 & 0 & 0 & 2 & 2 & 2 \\
\hline 2 & Stack block & 0 & 0 & 2 & 2 & 2 & 2 & 2 & 2 \\
\hline 3 & Stir in cup & 0 & 0 & 2 & 0 & 2 & 2 & 2 & 0 \\
\hline 4 & Drink from cup & 0 & 0 & 2 & 1 & 2 & 2 & 0 & 0 \\
\hline \multirow[t]{2}{*}{5} & Brush hair & 2 & 0 & 2 & 0 & 1 & 2 & 2 & 2 \\
\hline & Mean & 0.8 & 0 & 2 & 0.6 & 1.4 & 2 & 1.6 & 1.2 \\
\hline \multicolumn{10}{|c|}{ B Vocal imitation } \\
\hline & Sound: "aaah" & 1 & 0 & 0 & 0 & 2 & 2 & 1 & 1 \\
\hline & Sound: "Oy" & 1 & 0 & 0 & 0 & 2 & 1 & 1 & 1 \\
\hline & Mean & 1 & 0 & 0 & 0 & 2 & 1.5 & 1 & 1 \\
\hline \multicolumn{10}{|c|}{ C Facial imitation } \\
\hline & Tongue protrusion & 0 & - & 2 & - & 0 & 0 & 2 & 0 \\
\hline & Mouth opening & 0 & - & 0 & - & 0 & 1 & 2 & 1 \\
\hline & Smell flower & 2 & 0 & 1 & - & 0 & 2 & 1 & 2 \\
\hline & Mean & 0.66 & 0 & 1 & - & 0 & 1 & 1.67 & 1 \\
\hline \multicolumn{10}{|c|}{ D Motor imitation } \\
\hline & Wave bye-bye & 1 & 0 & 0 & - & - & 2 & 1 & 1 \\
\hline & Yawning & 0 & - & - & - & - & 1 & 0 & 2 \\
\hline & Touch ear-knee-nose & 0 & - & 0 & - & - & 1 & 0 & 1 \\
\hline & Mean & 0.33 & 0 & 0 & - & - & 1.33 & 0.33 & 1.33 \\
\hline \multicolumn{10}{|c|}{ E Object substitution } \\
\hline & Cup as hat & 0 & 0 & 0 & 0 & 1 & 2 & 1 & 1 \\
\hline & Drink from brush & 2 & 0 & 0 & 0 & 0 & 2 & 1 & 1 \\
\hline & Mean & 1 & 0 & 0 & 0 & 0.5 & 2 & 1 & 1 \\
\hline \multicolumn{2}{|c|}{ Mean A-E } & 0.73 & 0 & 0.93 & 0.33 & 1.0 & 1.6 & 1.2 & 1.13 \\
\hline
\end{tabular}

0, no imitation; 1 , partial imitation; 2 , full imitation; -, no successful presentation. 
indicated the maximum number of modellings possible for any child to observe $(15 \times 2)$. Some presentations were obviously excluded due to the child's imitation success, but for most of the omitted presentations other factors influenced the observation; that is, several trials were excluded due to lack of interest, attention, concentration, or motivation on the child's part. As shown in Table III, the tasks with the lowest number of presentations per child belonged to group $\mathrm{D}$ (motor imitation) while tasks belonging to group A (object manipulation) and B (vocal imitation) received the highest number of presentations.

In conclusion, the level of imitation seems to vary as a function of the type of task presented. Object manipulation tasks were most often imitated while motor and object substitution tasks displayed the lowest frequencies of observed imitation. However, as stated before, we did not succeed in presenting the motor imitation tasks as often as the object substitution tasks. Furthermore, wide variations in imitation were observed among the children with autism. As presented in Table II, three of the children with autism were responsible for almost all of the imitative responses observed (mean imitation scores 0.73 to 1.0 , cases 1,3 and 5). The two remaining children received scores of 0 and 0.33 , respectively. A comparison of the information in Tables I and II reveals that one of the children receiving a high imitation score (case 3 , mean score 0.93 ) had an estimated MA of only 33 months and also one of the lowest developmental quotients. In addition, it is worth noting that one child (case 3 ) showed complete imitation on all object manipulation tasks, and that another child (case 5) imitated both vocal imitation tasks completely.

\section{Comparison across the groups}

All of the tasks were presented to three normal 4-year-olds (CG1), and 10 of the imitation tasks were also administered to 28 healthy 12-month-old infants (CG2). Tables II and III contain information on the performance of CG1 in addition to the above presented results for the IA group while Table IV adds information concerning the obtained imitation scores for all the three groups studied. These scores indicate the ratios between number of observed imitative responses and the total number of presentations/ modellings for each task. Overall, the children in both comparison groups displayed a higher tendency to imitate than the autistic children.

The IA group compared with the 4-year-olds. None of the children with autism performed at the level of the nor-

TABLE III. Total frequencies of observed imitation and total number of successful presentations for five children with autism (IA group), and three normal 4 year olds (comparison group 1)

\begin{tabular}{|c|c|c|c|c|}
\hline & \multicolumn{2}{|c|}{$\begin{array}{l}\text { Total frequency of } \\
\text { imitation } 1\end{array}$} & \multicolumn{2}{|c|}{$\begin{array}{c}\text { Total number of } \\
\text { successful presentations }\end{array}$} \\
\hline & $\begin{array}{l}\text { IA group } \\
(n=5)\end{array}$ & $\begin{array}{c}C G 1 \\
(n=3)\end{array}$ & $\begin{array}{l}\text { IA group } \\
(n=5)\end{array}$ & $\begin{array}{c}C G 1 \\
(n=3)\end{array}$ \\
\hline A Object manipulation, sum & 13 & 12 & 37 & 22 \\
\hline 1 Drop block & 2 & 3 & 7 & 4 \\
\hline 2 Stack block & 3 & 3 & 10 & 3 \\
\hline Stir in cup & 2 & 2 & 7 & 5 \\
\hline Drink from cup & 3 & 1 & 8 & 5 \\
\hline 5 Brush hair & 3 & 3 & 5 & 5 \\
\hline B Vocal imitation, sum & 4 & 6 & 17 & 9 \\
\hline 6 Sound: "aaah!" & 2 & 3 & 9 & 3 \\
\hline 7 Sound: "Oy!" & 2 & 3 & 8 & 6 \\
\hline C Facial imitation, sum & 3 & 7 & 15 & 14 \\
\hline 8 tongue protrusion & 1 & 1 & 5 & 5 \\
\hline $9 \quad$ Mouth opening & 0 & 3 & 4 & 5 \\
\hline 10 Smell flower & 2 & 3 & 6 & 4 \\
\hline$D$ Motor imitation, sum & 1 & 7 & 7 & 14 \\
\hline 11 Wave bye-bye & 1 & 3 & 4 & 4 \\
\hline 12 Yawning & 0 & 2 & 1 & 5 \\
\hline 13 Touch ear-knee-nose & 0 & 2 & 2 & 5 \\
\hline E Object substitution, sum & 2 & 6 & 16 & 9 \\
\hline 14 Cup as hat & 1 & 3 & 8 & 4 \\
\hline 15 Drink from brush & 1 & 3 & 8 & 5 \\
\hline Total A-E & 23 & 38 & 92 & 68 \\
\hline
\end{tabular}

${ }^{1}$ Both full and partial imitations are accepted as instances of imitation. 
mal 4-year-olds when total scores were compared (see Table II). The child with autism that displayed the highest level of imitation received a mean score of 1.0 while the normal child with the lowest frequency received a mean score of 1.13. This difference in imitation tendencies is highlighted by the imitation ratios displayed in Table IV. The three normal 4-year-olds did obtain higher imitation ratios than the five children with autism on almost all imitation measures used. The only items on which the children with autism performed at or above the level of the 4-year-olds were two of the object manipulation ("stir in cup" and "drink from cup"), and one of the facial imitation tasks ("tongue protrusion"). When the comparison is limited to the four children with autism who did imitate we still find the same differences although the overall ratio for object manipulation tasks almost reaches the same level as for the normal 4-year-olds (0.46 compared with 0.59). Furthermore, the difference seems to be especially large for motor imitation and object substitution tasks.

The IA group compared with normal 1-year-olds. The 28 healthy 1 -year-olds in CG2 displayed a higher tendency to imitate object manipulation tasks than the children with autism. The mean imitation ratio observed is 0.80 compared with 0.35 for the IA group. None of the normal infants failed to imitate all of the object manipulation tasks while, in comparison, one of the children with autism failed to imitate (case 2). The level of imitation among the normal 1-year-olds was lower for facial and vocal imitation tasks but still higher than observed for the children

TABLE IV. Mean imitation ratios observed after modelling of 10 to 15 tasks to five children with autism ( 15 tasks), three normal 4 year olds (comparison group 1, 15 tasks), and 28 healthy 1 year olds (comparison group 2, 10 tasks)

\begin{tabular}{|c|c|c|c|c|c|}
\hline \multirow{2}{*}{\multicolumn{2}{|c|}{ Task }} & \multicolumn{2}{|c|}{ Autism group ${ }^{1}$} & \multicolumn{2}{|c|}{ Comparison } \\
\hline & & $\begin{array}{c}\text { A } \\
(n=5)\end{array}$ & $\begin{array}{c}\mathrm{B} \\
(n=4)\end{array}$ & $\begin{array}{c}\text { Group } 1 \\
(n=3)\end{array}$ & $\begin{array}{l}\text { Group } 2 \\
(n=28)\end{array}$ \\
\hline \multicolumn{6}{|c|}{ A Object manipulation } \\
\hline 1 & Drop block & 0.29 & 0.40 & 0.60 & 0.62 \\
\hline 2 & Stack block & 0.30 & 0.38 & 1.00 & 0.96 \\
\hline 3 & Stir in cup & 0.29 & 0.40 & 0.40 & 0.97 \\
\hline 4 & Drink from cup & 0.38 & 0.50 & 0.20 & 0.82 \\
\hline \multirow[t]{2}{*}{5} & Brush hair & 0.60 & 0.75 & 0.75 & 0.62 \\
\hline & Mean & 0.35 & 0.46 & 0.59 & 0.80 \\
\hline \multicolumn{6}{|c|}{ B Vocal imitation } \\
\hline 6 & Sound: "aaah" & 0.22 & 0.29 & 1.00 & 0.43 \\
\hline \multirow[t]{2}{*}{7} & Sound: "Oy" & 0.25 & 0.33 & 0.50 & 0.50 \\
\hline & Mean & 0.24 & 0.31 & 0.75 & 0.47 \\
\hline \multicolumn{6}{|c|}{ C Facial imitation ${ }^{2}$} \\
\hline 8 & Tongue protrusion & 0.20 & 0.20 & 0.20 & 0.35 \\
\hline 9 & Mouth opening & 0.00 & 0.00 & 0.60 & 0.50 \\
\hline \multirow[t]{2}{*}{10} & Smell flower & 0.33 & 0.40 & 0.75 & 0.41 \\
\hline & Mean & 0.20 & 0.21 & 0.52 & 0.42 \\
\hline \multicolumn{6}{|c|}{$D$ Motor imitation ${ }^{3}$} \\
\hline 11 & Wave bye-bye & 0.25 & 0.33 & 0.75 & - \\
\hline 12 & Yawning & 0.00 & 0.00 & 0.40 & - \\
\hline \multirow[t]{2}{*}{13} & Touch ear-knee-nose & 0.00 & 0.00 & 0.40 & - \\
\hline & Mean & 0.14 & 0.17 & 0.52 & - \\
\hline \multicolumn{6}{|c|}{ E Object substitution } \\
\hline 14 & Cup as hat & 0.13 & 0.17 & 0.75 & - \\
\hline \multirow[t]{2}{*}{15} & Drink from brush & 0.13 & 0.17 & 0.60 & - \\
\hline & Mean & 0.13 & 0.17 & 0.52 & - \\
\hline \multicolumn{6}{|c|}{ Overall } \\
\hline \multicolumn{2}{|c|}{10 tasks } & 0.29 & 0.36 & 0.60 & 0.62 \\
\hline \multicolumn{2}{|c|}{15 tasks } & 0.25 & 0.32 & 0.59 & - \\
\hline
\end{tabular}

${ }^{1}$ Column $A$ gives the mean ratios obtained for all five children with autism while the ratios in column $B$ exclude the child that failed to show any imitation (case 2 ).

${ }^{2}$ Autism group: $n=4$ for $A$ and $n=3$ for $B$ (case 4 not included).

${ }^{3}$ Autism group: $n=3$ for $A$ and $n=2$ for $B$ (cases 4 and 5 not included). 
with autism. The observation that the children with autism in our sample displayed a lower tendency to imitate stands even when the child (case 2) who failed to imitate is excluded from the analysis, although the observed differences decrease. In conclusion, it seems fair to state that the five children with autism imitate to a lesser degree than the normal 1-year-olds.

\section{DISCUSSION}

Although no conclusions can be made on the basis of a pilot study our findings seem to suggest that (1) the highest level of imitation in children with autism is achieved in object manipulation and vocal imitation tasks, (2) the normal children displayed a higher incidence of imitation overall than the children with autism, and (3) tasks requiring object substitution may be less frequently imitated by children with autism. Moreover, the children with autism in our study displayed quite large variations in imitative tendencies. Although these preliminary suggestions might seem speculative based as they are on observations of only five children with autism, the difficulty we experienced in eliciting imitation as well as the observed variation in imitation must be taken into account when discussing imitation among children with infantile autism.

It is important also to highlight the very low rate of imitation noted for the motor and object substitution tasks. It might be that these two types of tasks are especially difficult for children with autism. Among normal children we can usually expect a rapid increase in imitation of such acts during the second and third year of life (e.g. Bates, 1979; Belsky and Most, 1981). Thus, these tentative observations are in accordance with previous reports indicating that children with autism have difficulties imitating more symbolic acts as well as motor tasks (Hammes and Langdell, 1981; Riguet et al., 1981; Sigman and Ungerer, 1984; Rogers and Pennington, 1991).

It is furthermore worth noting that the children with autism participating in this study were not compared with matched controls. Since tasks involving symbolic manipulation were especially difficult for the children with autism one would expect the observed differences between the children with autism and the comparison groups to increase if a matched control group was used instead. This assumption is supported by the normal 4 year olds' performance and by previous research (see Dawson, 1987). However, since no control group matched for mental age was included we cannot rule out the possibility that mental retardation in part explains the low levels of symbolic imitation (= object substitution tasks) observed in our pilot study. Even if some of the autistic children had a normal or near normal IQ, the sample is too small to allow any definite conclusions concerning how much should be attributed to the children's diagnosis and how much could be accounted for by mental retardation.

Three additional factors must also be considered when interpreting our results. The first factor relates to the fact that a pre-set order of presentation was used. Thus, one cannot rule out the possibility that the children performed best initially when they were not affected by fatigue. This is however not fully supported by the children's observed behaviour: as it happened the object substitution tasks presented late in each session did catch all the children's attention and we did succeed in presenting both these tasks to all the five children with autism. In contrast, we often experienced difficulties when trying to present the motor tasks although they were demonstrated earlier in the session. The second factor deals with the way the two vocal imitation tasks were presented. It is possible that the hand doll used for presentation confounded the tasks since it can be viewed as a pretend figure. Thus it becomes difficult to differentiate between the children's performance on the vocal imitation tasks and their performance on the object substitution tasks. There is evidence indicating that the capacity for pretend play is delayed among children with autism (Frith, 1989). Finally, the third factor relates to the motor imitation tasks. We were not very successful in demonstrating these tasks to the children with autism which increases the uncertainty as to how to interpret the low level of motor imitation observed. Furthermore, two of the tasks ("waves bye-bye" and "yawning") might be judged more as social gestures while the third presentation ("touch ear-knee-nose") probably is more of a strict motor task.

In spite of the fact that none of the tasks were constructed primarily for children with autism we experienced very few reactions from the autistic children concerning the "childishness" of the tasks used. However, one child with autism having an IQ within the normal range was an exception (case 5). He did comment "You can't do that" when "drinking from brush" was presented. In contrast, all three normal 4-year-olds did comment upon the tasks (e.g. verbal comments like "this is ridiculous"). In other words, the 4-year-olds indicated that they were sceptical, but this did not seem to affect their overall performance (except for object manipulation tasks on which they displayed lower tendencies to imitate than the normal 1-year-olds).

Most studies of children with autism use relatively older subjects. However, as Gillberg et al. (1990) have pointed out, we need observations on the early development of children with autism. Since there are probably multiple causes of autism, imitation might function differently in various subgroups of the disorder. One way of studying this could be to include some imitation tasks, tapping different domains, in a standard evaluation procedure for young children with suspected autism. Another possibility 
would be to study different subgroups specifically in order to map their spontaneous use of imitation as well as their ability to imitate when prompted.

An additional argument for studying imitation among children with autism is the individual variations noted in the present study. This is an issue that has come more and more into focus among those studying imitation in normal development (see Speidel and Nelson, 1989). No longer is imitation seen as a skill that all children possess to the same degree. Instead, imitation is often viewed as a strategy that some children use more than others. Individual differences have for example been noted for verbal imitation (Bloom et al., 1974; Nelson et al., 1985), non-verbal imitation (Heimann and Nelson, 1986), and even among neonates (Field, 1982; Heimann et al., 1989).

In conclusion, future studies have to: (a) adopt strategies to further investigate imitation in very young children with autism or suspected autism and compare it to that of other mentally handicapped children as well as to normal children; (b) study the comparative developmental sequence of pretend-like imitation and non-symbolic imitation; (c) follow children with autism longitudinally in order to study individual variations in tendencies to imitate; (d) investigate imitation among children with autism belonging to different clinical subgroups of the disorder.

\section{Acknowledgements}

This project was supported by grants from Allmänna Barnhuset, Stockholm, and Sven Jerring Fonden, Stockholm to Mikael Heimann, and from the Swedish Inheritance Fund to Christopher Gillberg. Portions of this paper were presented at the conference on Experimental Psychology and the Autistic Syndromes held at Durham, UK, 18-20 April 1990. The authors wish to thank Dr Uta Frith for helpful suggestions on the coding of the videotapes, Drs Keith E. Nelson and Joseph Schaller for valuable comments on an earlier draft of the article, and Kristina Svärd for important assistance. We also wish to thank all the participating children and their families.

\section{REFERENCES}

Alin-Åkerman B and Nordberg L (1980) Griffiths utvecklingsskalor I och II. Psykologiförlaget, Stockholm (in Swedish).

American Psychiatric Association (1980) Diagnostic and Statistical Manual of Mental Disorders. APA, Washington, DC.

American Psychiatric Association (1987) Diagnostic and Statistical Manual of Mental Disorders, revised 3rd edn. APA, Washington, DC.

Baron-Cohen S, Leslie AM and Frith U (1985) Does the autistic child have a theory of mind? Cognition, 21, 37-46.

Bates E (1979) The Emergence of Symbols: Cognition and Communication in Infancy. Academic Press, New York.

Belsky J and Most RK (1981) From exploration to play: A crosssectional study of infant free play behavior. Developmental Psychology, 17, 630-639.

Bergès J and Lézine I (1965) The Imitation of Gestures. Clinics in Developmental Medicine No. 18 (Transl. by AH Permelee Jr). Heinemann Medical Books, London.
Bloom L, Hood L and Lightbown P (1974) Imitation in language development: If, when and why. Cognitive Psychology, 6, 380-420.

Dahlgren SO and Gillberg C (1989) Symptoms in the first two years of life. A preliminary population study of infantile autism. European Archives of Psychiatry and Neurological Sciences, 238, 169-174.

Dawson G (1987) The role of abnormal hemispheric specialisation in autism. In: Neurobiological Issues in Autism (Eds E Schopler and GB Mesibov). Plenum Press, New York.

Dawson G and Galpert L (1987). Mother's use of imitative play for facilitating eye contact and toy play in autistic children. Paper presented at the Biennial Meeting of the Society for Research in Child Development, Baltimore, Maryland, USA.

DeMyer MK, Alpern GD, Barton S, DeMyer WE, Churchill DW, Hingtgen JN, Bryson CQ, Pontius W and Kimberlin C (1972) Imitation in autistic, early schizophrenic, and non-psychotic subnormal children. Journal of Autism and Childhood Schizophrenia, 2, 264-287.

Field TM (1982) Individual differences in the expressivity of neonates and young infant. In: Development of Nonverbal Behavior in Children (Eds W Pontius and C Kimberlin). Springer-Verlag, New York.

Ford RA (1989) The psychopathology of echophenomena. Psychological Medicine, 19, 627-635.

Frith U (1989) Autism: Explaining the Enigma. Basil Blackwell, Oxford.

Gillberg C, Ehlers S, Schaumann H, Jakobsson G, Dahlgren SO, Lindblom R, Bågenholm A, Tjuus T and Blidner E (1990) Autism under age 3 years: a clinical study of 28 cases referred for autistic symptoms in infancy. Journal of Child Psychology and Psychiatry, 31, 921-934.

Griffiths R (1954) The Abilities of Babies. University of London Press, London.

Hammes JGW and Langdell T (1981) Precursors of symbol formation and childhood autism. Journal of Autism and Developmental Disorders, 11, 331-346.

Heimann M (1991) The relationship between imitation during the first three months of life and imitation at 12 months of age: Preliminary findings from a follow-up. Poster presented at the biennial meeting of the Society for Research in Child Development, Seattle, Washington, USA.

Heimann M and Nelson KE (1986) The relationship between nonverbal imitation and gestural communication in 12 to 15 months old infants. Göteborg Psychological Reports, 16, No. 2.

Heimann M, Nelson KE and Schaller J (1989) Neonatal imitation of tongue protrusion and mouth opening: Methodological aspects and evidence of early individual differences. Scandinavian Journal of Psychology, 30, 90-101.

Hertzig ME, Snow ME and Sherman M (1989) Affect and cognition in autism. Journal of the American Academy of Child and Adolescent Psychiatry, 28, 195-199.

Jones V and Prior M (1985) Motor imitation abilities and neurological signs in autistic children. Journal of Autism and Developmental Disorders, 15, 37-46.

Krug DA, Arick J and Almond P (1980) Behavior checklist for identifying severely handicapped individuals with high levels of autistic behavior. Journal of Child Psychology and Psychiatry, 21, 221-229.

LeCouteur A, Rutter M, Lord C, Rios P, Robertson S, Holdgrafer M and McLennan J (1989) Autism diagnostic interview: A standardized investigator-based instrument. Journal of Autism and Developmental Disorders, 19, 363-387. 
Leslie AM (1987) Pretence and representation: the origins of a "theory of mind". Psychological Review, 94, 412-426.

Lovaas OI, Freitas L, Nelson K and Whalen K (1967) The establishment of imitation and its use for the development of complex behavior in schizophrenic children. Behavioral Research and Therapy, 5, 171-181.

Morgan SB, Cutrer PS, Coplin JW and Rodrique JR (1989) Do autistic children differ from retarded and normal children in Piagetian sensorimotor functioning? Journal of Child Psychology and Psychiatry, 30, 857-864

Nadel J and Fontaine M (1989) The communicative function of gestural and verbal synchronized imitation in normal prelinguistic toddlers and autistic children: A comparative study. Paper presented at the Fourth World Congress of the World Association for Infant Psychiatry and Allied Disciplines, Lugano, Switzerland.

Nelson KE, Baker ND, Denninger M, Bonvillan JD and Kaplan BJ (1985) Cookie versus do-it-again: Imitative-referential and personal-social-syntactic-initating languages styles in young children. Linguistics, 23, No 43-454.

Nelson KE, Heimann M, Abuelhaija LA and Wroblewski R (1989) Implications for language acquisition models of children's and parents' variations in imitation. In: The Many Faces of Imitation in Language Learning (Eds GE Speidel and KE Nelson). Springer-Verlag, New York.

Ohta M (1987) Cognitive disorders of infantile autism: A study employing the WISC, spatial relationship conceptualization, and gesture imitation. Journal of Autism and Developmental Disorders, 17, 45-62.

Ricks DM and Wing L (1975) Language, communication, and the use of symbols in normal and autistic children. Journal of Autism and Childhood Schizophrenia, 5, 191-222.

Riguet CB, Taylor ND, Benaroya S and Klein LS (1981) Symbolic play in autistic, Down's, and normal children of equivalent mental age. Journal of Autism and Developmental Disorders, 11, 439-448.

Ritvo S and Provence S (1953) Form perception and imitation in some autistic children: Diagnostic findings and their contextual interpretation. The Psychoanalytic Study of the Child, $\mathbf{8}$, 155-161.

Rogers SJ and Pennington BF (1991) A theoretical approach to the deficits in infantile autism. Development and Psychopathology, 3, 137-162.

Sauvage D, Hameury L, Adrien JL, Larmande C, Perrot-Beaugerie A, Barthelémy C and Peyraud A (1987) Signes d'autisme avant deux ans. Evaluation et signification. Annales de Psychiatrie, 3, 418-424.

Shapiro R and Lucy P (1978) Echoing in autistic children: A chronometric study of semantic processing. Journal of Child Psychology and Psychiatry, 20, 373-378.

Sigman M and Ungerer JA (1984) Cognitive and language skills in autistic, mentally retarded, and normal children. Developmental Psychology, 20, 293-302.

Speidel GE and Nelson KE (1989) A fresh look at imitation in language learning. In: The Many Faces of Imitation in Language Learning (Eds GE Speidel and KE Nelson). SpringerVerlag, New York.

Wing L, Gould J, Yeates SR and Brierley LM (1977) Symbolic play in severely mentally retarded and in autistic children. Journal of Child Psychology and Psychiatry, 18, 167-178. 


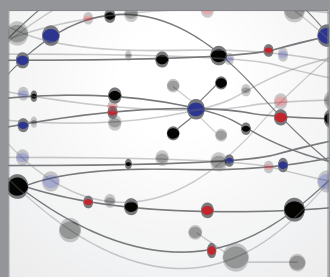

The Scientific World Journal
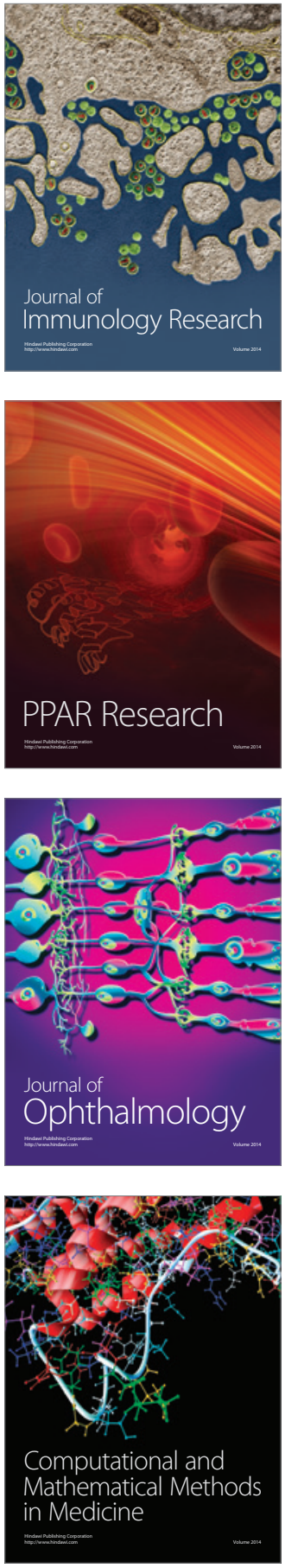

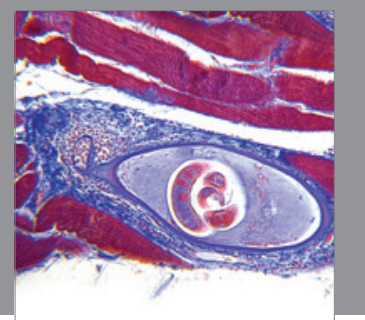

Gastroenterology

Research and Practice
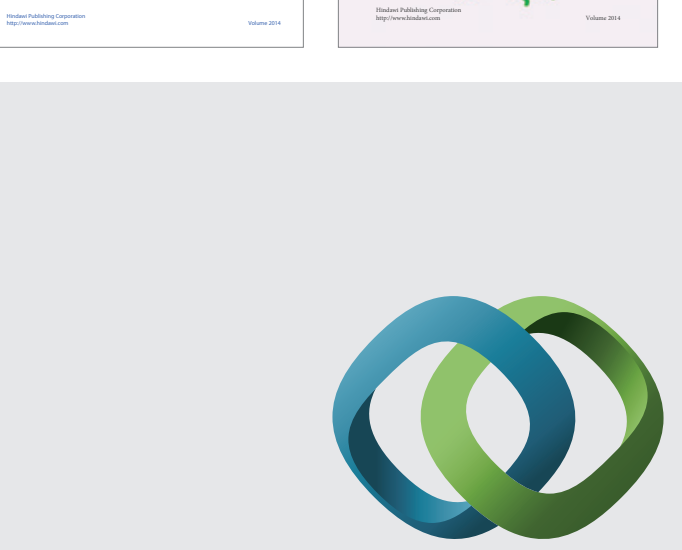

\section{Hindawi}

Submit your manuscripts at

http://www.hindawi.com
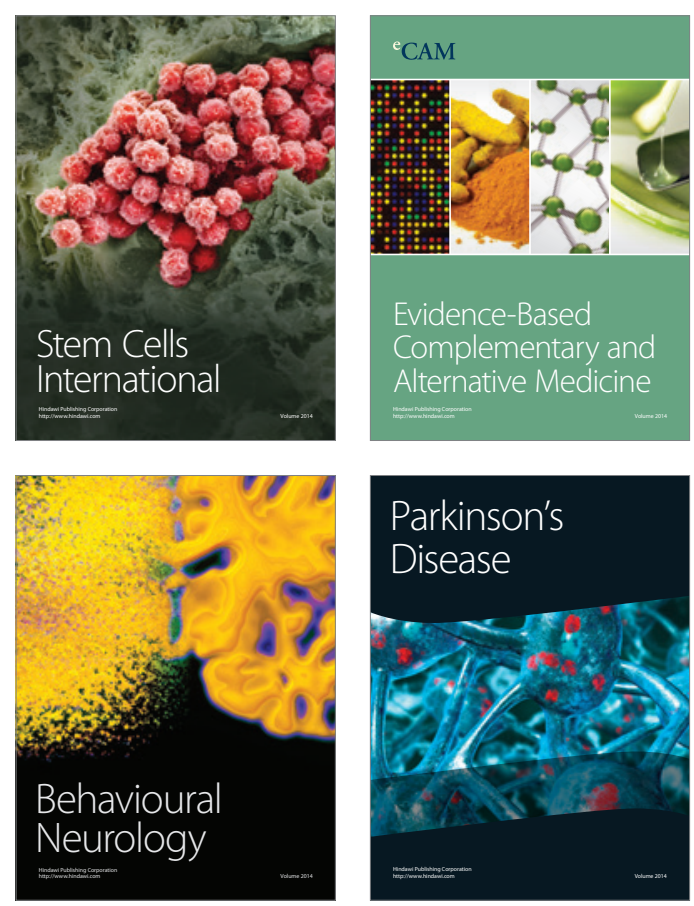

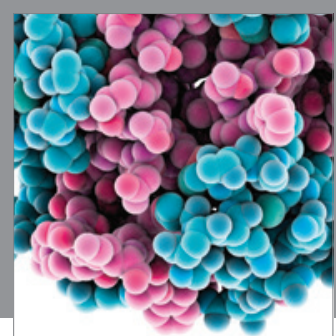

Journal of
Diabetes Research

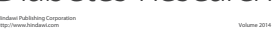

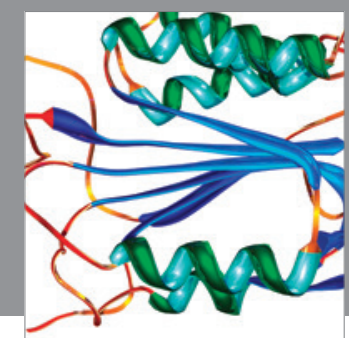

Disease Markers
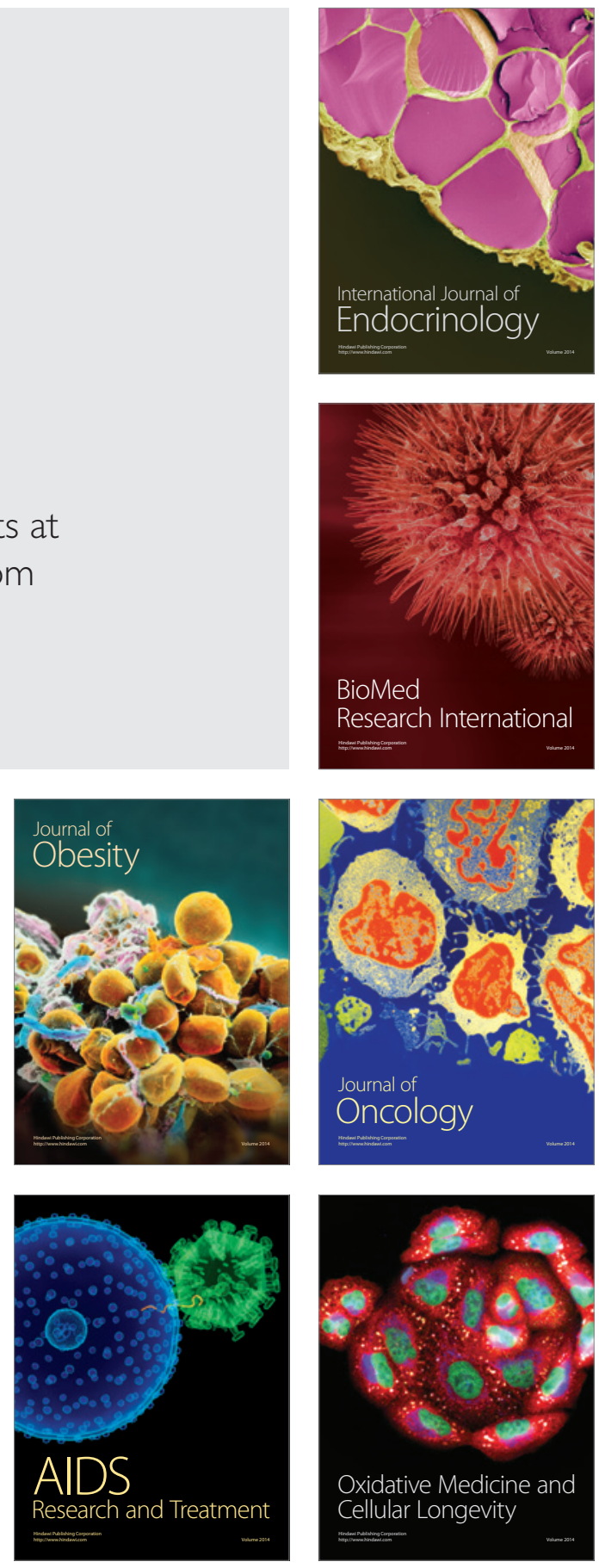